\title{
Ivo de la Cortina y su obra «Antigüedades de Itálica» (1840): Una revista arqueológica malograda
}

\author{
Alicia Maㅡ Canto \\ Univ. Autónoma de Madrid
}

\begin{abstract}
... Hablo sin rebozo, con la franqueza que tengo por costumbre, para que se vea de quién procede el abandono de las excavaciones y la persecución que he soportado en el espacio de dos años para frustar mi empeño.. Ivo de la Cortina (El Sevillano, 9-6-1841)
\end{abstract}

\section{Resumen}

Este trabajo es un avance del perfil biográfico (en preparación) de uno de los menos conocidos arqueólogos españoles del siglo XIX: Ivo de la Cortina y Roperto, autor de unas valiosas pero cortas y desgraciadas excavaciones en el Forum de Itálica (Sevilla) entre 1839 y 1840. Un desconocido anuncio de prensa de su inconclusa obra por fascículos, Antigüedades de Itálica, nos permite aclarar el título real de la misma y acercarnos a la concepción y práctica de la Arqueología de su autor, así como lamentar la pérdida de lo que esta publicación también prometía como una embrionaria, y por desgracia fallida, revista científica española de debate arqueológico. Envidias, resentimientos y piques, personales y políticos, teñidos con algo de aldeanismo, arruinaron -una vez más- a un buen profesional y una buena iniciativa.

\section{Abstract}

This paper is an advance on the biographical study (forthcoming) of one of the lesser known Spanish archaeologists of the XIXth. Century, Ivo de la Cortina y Roperto, author of valuable but short and unfortunate excavations in the Forum at Italica (Seville) between 1839 and 1840. A previously unknown press advert of his unfinished work, published in fascicle form, Antigüedades de Itálica, allows us to clarify its actual title, and the author's perception of Archaeology and its practice at the time. This paper also explores what could have been the first Spanish scientific Archaeological Journal and discussion Forum, if only colleagues had responded to Cortina's request for co-operation. Unfortunately as the author himself claimed, personal and political jealousies, resentment and piques frustrated, once again, a good professional and a good iniciative.

Ivo de la Cortina y Roperto -o Ibo, Yvo, Roberto, Roperto y Corrochano, o R. y Corrochano, pues todas estas variantes de firma o citas he encontrado de él y sobre él en distintos momentos de su vida y memoria-, nacido el 1 de diciembre de 1805 en Villanueva y la Geltrú (Barcelona), fue, entre otras varias facetas, uno de los arqueólogos españoles justamente merecedores de tal consideración durante el siglo XIX. También uno de los pocos que obtuvieron un reconocimiento internacional por su trabajo. Y, aunque no procedía del mundo académico ni perteneció nunca a él, fue admitido como miembro en distintas sociedades científicas a lo largo de su vida.

1. El cese le llegó de la Junta de Sevilla que emergió del pronunciamiento revolucionario de septiembre de 1840. Según el propio Cortina escribirá el 24 de octubre siguiente, su cese fue injusto y se debió "a sus ideas liberales y progresistas». $\mathrm{Y}$ aunque consta que una semana después, el 31 de octubre de 1840, la Academia de Sevilla le nombra otra vez «director de las excavaciones», desestimando así la separación que habían dispuesto las nuevas autoridades de la regencia de Espartero, en la realidad los trabajos en Itálica no pro-
A pesar de ello, como otros muchos anticuarios españoles, de su siglo y de los anteriores, sólo rara vez se le hallará citado en la bibliografía arqueológica posterior, y siempre en relación con sus breves y problemáticas pero fructíferas excavaciones en el Forum de la noble Itálica, que se desarrollaron, entre incontables dificultades, desde el 30 de enero de 1839 hasta el comienzo del otoño de 1840, cuando fue relevado del cargo por razones políticas ${ }^{1}$, si bien ya desde el mismo comienzo, como él cuenta, su trabajo venía siendo objeto "de las intrigas de un hombre miserable» ${ }^{2}$.

En la historia de las excavaciones de la desgraciada ciudad bética quizá sea este bienio el

gresaron más. Este inesperado resultado de su apoyo ( «...fui de los que más trabajaron para que se verificase el pronunciamiento en favor de la revolución...») le hace abandonar la causa del regente y abrazar la de la joven Isabel II.

2. I. de la Cortina, "Antigüedades de Itálica», Semanario Pintoresco Español, 1845 (1), 29-31, espec. 30. No hay referencias precisas para saber de quién se trata, pero vid. sobre ello in fine, y el texto de las notas 37 y 39. 
más contradictorio, pues los intentos de salvar las ruinas y sus nuevos excelentes hallazgos para su contemplación y estudio tenían lugar a la vez que, a pocos metros de distancia, se producía el más desconsiderado expolio, también oficial, con destino a las obras de reparación de la carretera Sevilla-Mérida, al que acompañaban, a pesar de las protestas de los más cultos y sensibles ciudadanos hispalenses, las ventas subrepticias de antigüedades a españoles y extranjeros. Don Ivo sería sucedido algo más tarde en la dirección de las excavaciones por el que llegaría a ser su buen amigo y colaborador, el erudito natural de Baena (Córdoba) José-Amador de los Ríos y Serrano, no sin que éste defendiera su trabajo en diversas ocasiones ${ }^{3}$. Ambos pertenecían -Cortina menos

3. Por ejemplo en su dolido artículo «El Alcázar de Sevilla. Las ruinas de Itálica», en el semanario La Floresta Andaluza $\mathrm{n}^{\mathrm{o}} 46$, del viernes 12 de enero de 1844, 241-243 ("...el laborioso celo de don Ivo de la Cortina...». José-Amador, nacido en 1818 , era trece años menor que Cortina.

4. M. Gómez Moreno y J. Pijoán, Materiales de Arqueología Española, cuaderno primero, Madrid, 1912, 7. Se referían con esta denominación a arqueólogos modernos y comprometidos, de la generación "que presidían eruditos como $D$. José Amador de los Ríos», varios de cuyos miembros impulsaron al Estado español a patrocinar, en la segunda mitad del XIX, obras de empaque europeo como los Monumentos Arquitectónicos de España o el Museo Español de Antigüedades. Todos ellos se distinguían por ser «humanistas» en un sentido amplio, y no era raro que practicaran varias especialidades científicas y, sobre todo, literarias.

5. Demetrio de los Ríos y Serrano, ilustre arquitecto andaluz muy vinculado desde su adolescencia a la ciudad de Itálica, fue entre 1860 y 1868 director de sus excavaciones. Conoció bien a Ivo de la Cortina, con el que llegó a colaborar a través de su ya citado hermano mayor, y muchas de cuyas notas y dibujos heredó (que se conservan actualmente en el Museo Arqueológico de Sevilla). Pero la obra en la que don Demetrio más le citaba, terminada hacia 1879 (y por tanto como mínimo trece años anterior a la de Gali que se dirá a continuación) ha permanecido desconocida e inédita hasta nuestros días. Actualmente se halla en proceso de edición por quien suscribe: Itálica. Historia y descripción artística de esta infortunada ciudad y de sus ruinas. El manuscrito perdido de don Demetrio de los Ríos. Introducción, edición, notas y comentarios de Alicia $M^{a}$ Canto, en elaboración (patrocinado por la Fundación Itálica de Estudios Clásicos, Sevilla, publicación prevista para fines de 2004).

6. A. Gali y Lassaletta, Historia de Itálica, municipio y colonia romana, Sevilla, 1892 (reed. Sevilla, 2001), especialmente págs. 206-211; las págs. 209-211 consisten en la transcripción de un manuscrito de Cortina donde inventaría diversos objetos hallados el foro y depositados por él en el archivo y en el almacén del «Gobierno político» de Sevilla.

7. Rodrigo-Amador de los Ríos y Fernández Villalta (18431917), hijo de José-Amador y sobrino de Demetrio, continuó la saga familiar al hacerse cargo de las excavaciones del anfiteatro desde 1911. La cita a la que me refiero está afortunado- a la que don Manuel Gómez Moreno llamó "aquella estentórea generación»"

Entre lo publicado (hay referencias anteriores todavía inéditas ${ }^{5}$ ) es Aurelio Gali Lassaletta quien le presta importancia y elogios por primera vez en 1892, al comentar aquella campaña arqueológica, que vino en describir muy expresivamente como "el martirologio de don Ivo" ${ }^{6}$. Años después, Rodrigo-Amador de los Ríos, hijo de JoséAmador, se refiere a él como "el entusiasta don Ibo de la Cortina, del que nadie se acuerda» ${ }^{7}$. Casi medio siglo más tarde, Antonio García y Bellido, si bien con una breve referencia ${ }^{8}$, avivó su recuerdo para la moderna generación de estudiosos de Itálica ${ }^{9}$.

Aunque en dos obras recientes con marcado acento historiográfico sus autores se han fijado

en su artículo «El anfiteatro de Itálica. Noticias acerca de este monumento y de las excavaciones que en él, de orden del Gobierno, se practican", Revista de Archivos, Bibliotecas y Museos 5-6, 1916 (1), 381-410, especialmente 395-396; este artículo tenía un carácter introductorio, y en él hacía un repaso historiográfico de la ciudad desde el siglo XVI, y de los trabajos en ella habidos; en la nota 3 de la pág. 396 se hace eco de la queja de Ivo de la Cortina que quedó recogida supra en la nota 2. Pero lo del ingrato olvido no afectaba sólo a Cortina: en su pág. 404, al hablar del anfiteatro y deplorar "el espectáculo verdaderamente vergonzoso y triste» que ofrecía el edificio en 1911, lamenta también que "...habiase borrado ya de la memoria de todos... el recuerdo de las (excavaciones) practicadas con tanto acierto como fortuna por mi amado pariente D. Demetrio de los Ríos... cuyo nombre suena allí como extraño, cuando tanto le debe el monumento, y en él debia estar en honrosa forma conmemorado".

8. A. García y Bellido, Colonia Aelia Augusta Itálica, Madrid, 1960, 59-60, rápida noticia donde califica la campaña de «sonadas excavaciones».

9. Suelen ser reseñas cortas y basadas en lo conocido, por ejemplo N. Chisvert Jiménez, «Reflexiones sobre el empleo de topónimos y la descripción de edificios italicenses en obras antiguas», Habis 19, 1987-1988, 565-585, espec. 572573 y 579-580 (donde alude como nuevos sólo a los datos publicados por Cortina en La Gaceta de Madrid en 1839 y atribuye a éste algunas confusiones) y P. León, «Las ruinas de Itálica. Una estampa arqueológica de prestigio», $L a$ Antigüedad como argumento. Historiografía de Arqueología e Historia Antigua en Andalucía, edd. J. Beltrán y F. Gascó, Sevilla, 1993, 29-61, especialmente 53-54, donde lamenta «la ausencia de documentación» (aunque al menos un ejemplar de los primeros fascículos publicados por Cortina se guardaba en la Biblioteca Colombina de Sevilla). Ambas autoras extienden las excavaciones hasta 1842, pero el propio Ivo de la Cortina dice que «...decayeron a fines del año 1839... y perecieron luego en 1840» (cf. art. en nota 2). J.M. Luzón Nogué, en su breve guía de la nova urbs (La Itálica de Adriano, Sevilla, 1979), al hablar de las excavaciones (pp. 1721), no citó a Ivo de la Cortina ni a Demetrio de los Ríos (pero $c f$. ahora la nota siguiente). Por último en A. Caballos Rufino, J. M. Fatuarte y J. M. Rodríguez Hidalgo, Itálica arqueológica, Sevilla, 1999, 46 (fugaz referencia) y 45 (lámina de portada de Escabaciones de Itálica). 
algo más en la persona, o han facilitado de él algunos datos biográficos nuevos ${ }^{10}$, hace tiempo que el agitado, complejo, en momentos tristísimo, pero en su conjunto fascinante periplo vital de Ivo de la Cortina merece un estudio más detenido, que ponga de relieve también sus todavía más desconocidas aportaciones en torno a otras importantes ciudades hispanorromanas, como Mérida, Tarragona, Murcia o Bilbilis.

Valga como ejemplo de estos trabajos anteriores y posteriores a los de Itálica su magnífico plano topográfico de Mérida, en el que aparecen cuidadosamente ubicados sus restos arqueológicos visibles. Don Ivo conocía bien la vieja capital lusitana, ya que antes de llegar destinado ("ascendido", dice alguna fuente) al Gobierno Civil de Sevilla se hallaba en el de Badajoz, desde el que se le comisionó, en junio de 1838 y de Real Orden, para pasar a estudiar la ciudad y colaborar a la instalación del nuevo Museo de Arqueología en el desamortizado convento de Santa Clara. Producto tardío de estos muy poco conocidos trabajos es el plano que aquí reproduzco, dibujado por Cortina en 1867, sin duda sobre la base de sus estudios de hacía casi veinte años, y grabado por el célebre litógrafo Pic de Leopold (lám. 1). Está inspirado en el ejecutado años atrás y publicado por A. de Laborde, pero contiene más detalles ${ }^{11}$.

Mientras tal estudio sobre don Ivo avanza ${ }^{12}$, quisiera con estas páginas dar a conocer uno de los no muchos escritos de Cortina que llegaron a ver la luz y que, dentro de su brevedad, es capaz de transmitirnos lo que este simple funcionario de la Administración, arqueólogo de vocación y práctica y dotado de un gran sentido de lo que es colectivamente útil, pensaba acerca de la

10.F. Fernández Gómez, Las excavaciones de Itálica y don Demetrio de los Ríos a través de sus escritos, Córdoba, 1998, 87 y 90-93, con diversas referencias de prensa y citas de sus trabajos y desgracias. J. M. Luzón Nogué, Sevilla la Vieja. Un paseo histórico por las ruinas de Itálica, Sevilla, 1999, espec. 74-81, aporta por primera vez algunas noticias nuevas sobre su vida laboral a partir del expediente funcionarial de Cortina, que se conserva en el Archivo General de la Administración del Estado, hoy en Alcalá de Henares (ref. 6512 EC).

11. Aunque este plano es relativamente conocido, e incluso alguna vez se ha hecho una tirada de las que en Mérida tradicionalmente decoran casas y comercios, donde a veces se lo puede ver, lo cierto es que Ivo de la Cortina, sus trabajos o sus dibujos no suelen ser conocidos ni citados en la bibliografía emeritense habitual. Varios de ellos los ofreceré más adelante, en el marco del estudio que cito a continuación. Ésta en concreto estaba destinada a ser la lámina primera de su también truncada obra, que arriba a la izquierda él denomina aún Topografía de la Arqueología
Arqueología y de cómo debía sacársele mayor provecho científico. En segundo lugar, aclara algunas vacilaciones que existen en la bibliografía acerca del verdadero nombre de su principal y frustrada obra sobre Itálica. Y, sobre todo, nos permite conocer por primera vez cuál era el propósito del autor al iniciar esta obra y quizá lo que también pretendía con ella: sería el germen de la que hubiera podido llegado a ser, si la memoria no me falla, la primera revista científica de tema sólo arqueológico en España.

Durante el propio año de 1839, ante la importancia de los hallazgos en sus excavaciones en el foro (de los que envía relaciones puntuales, entre otras instituciones y organismos, al Gobierno, periódicamente publicadas en la Gaceta de Madrid), Cortina siente la necesidad de poner al alcance de los expertos y aficionados en general una publicación en la que se reseñen estas novedades. En este sentido el Bosquejo de Itálica de Justino Matute y Gaviria, de 1827, además de no contener grandes novedades (Gali acredita que Matute «lo calcó en los trabajos del padre Zevallos, Masdeu y Laborde» ${ }^{13}$ ), quedaba ya retrasado en su información, siendo además sus ilustraciones de una notable mediocridad, mientras que Cortina, entre sus muchas habilidades, contaba las de ser un aceptable pintor, dibujante e ilustrador gráfico $^{14}$. En suma, a partir de diversas láminas que tenía ya preparadas, el autor pensó editar una obra general por fascículos, con la ayuda de suscriptores fijos, como era usual por la época y a lo que su personal situación seguramente le obligaba (cf. infra).

Tanto acerca del título real de la obra como del número de fascículos que de ella llegaron a ver la luz y su extensión primitiva existen vacila-

Monumental de la Península Ibérica, y que tengo en fase de reedición. Hallé la lámina que ahora ofrezco en la Biblioteca Nacional de Madrid, dentro de la colección de estampas sueltas, sign. M $13 \mathrm{v}$.

12. Alicia $\mathrm{M}^{\mathrm{a}}$ Canto, «Ivo de la Cortina y Roperto: Arqueólogo, liberal y mártir», en preparación, con diversas obras, datos y documentos inéditos.

13. J. Matute y Gaviria, Bosquejo de Itálica ó Apuntes que juntaba para su historia, Sevilla, 1827. La denuncia del plagio en A. Gali Lassaletta, op.cit., 268 y passim. Era más grave la copia de una obra que se mantenía aún inédita, como lo estaba por entonces aún (y lo estaría hasta 1886) la elaboradísima La Itálica, del erudito jerónimo Fr. Francisco de Zevallos.

14. La cortísima referencia biográfica de la Enciclopedia Espasa (s.v., col. 1059) le cita como discípulo de José (de) Madrazo, copista de diversas obras del Museo del Prado y colaborador asiduo en revistas como El Album. J. M. Luzón Nogué (op.cit., 74) añade a lo dicho sus colaboraciones en el Semanario Pintoresco Español y El Universal. 


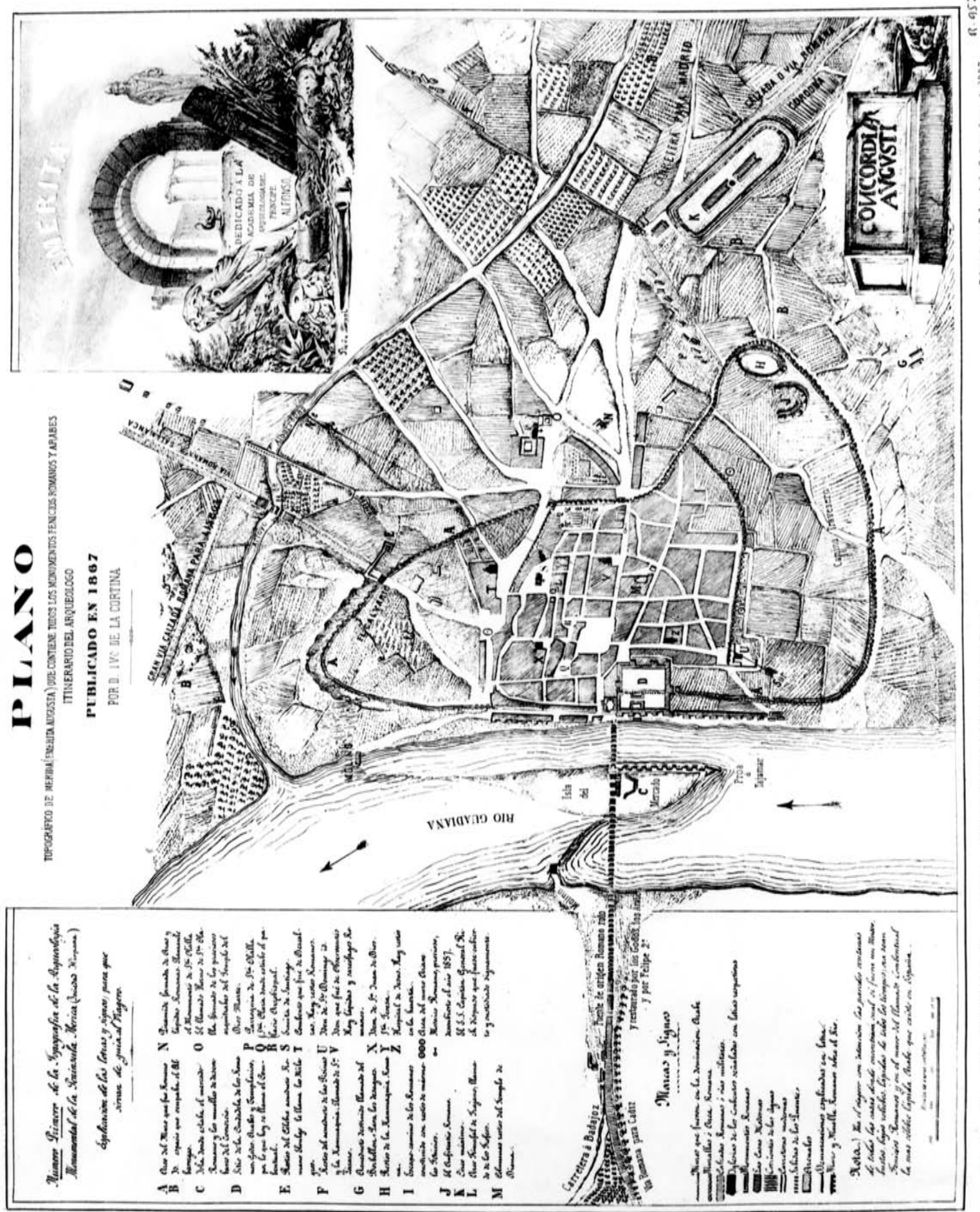


ciones y discrepancias en la bibliografía reciente, en parte debidas al hecho comprobado de su casi completa ausencia de las bibliotecas públicas. Esto ya ocurría en 1892, pues Aurelio Gali, como veremos más abajo ( $c f$. nota 24$)$, afirma que en la propia Sevilla, el lugar de edición, los ejemplares "habian desaparecido, no conservándose arriba de cuatro", lo que no deja de resultar asombroso y es buena muestra de una mala suerte que perseguiría a nuestro autor incluso después de su muerte.

Hasta donde he podido saber, de la obra concebida no llegaron a publicarse más de 54 páginas (correspondientes a 6 fascículos de los proyectados). Así lo confirma el epigrafista alemán Emil Hübner cuando veinte años después, durante su primer viaje a la Península, pudo consultarlos, con sus litografías, en la biblioteca de Madrid del académico y numismatista Antonio Delgado ${ }^{15}$, así como el ejemplar más completo conservado en Sevilla que citaré. Sin embargo, hay algunos indicios para pensar que el manuscrito preparado era más extenso, ya que el mismo editor del CIL lo cita en la bibliografía del Supplementum como "Ios(ephus, sic) de la Cortina, Antigüedades de Italica, folletin ms. $p$. 147» ${ }^{16}$. De este número casi triple de páginas pensé que se podía deducir que en algún otro momento, quizá durante su visita a Sevilla de 1880, Hübner hubiera podido consultar allí un manuscrito original y más extenso, o al menos hasta donde Cortina lo hubiera dejado.

Existen noticias entre los papeles de los hermanos José Amador y Demetrio de los Ríos, recientemente conocidos, en el sentido de que Cortina facilitó a José Amador, para la Historia de Itálica que éste preparaba y que quedó también interrumpida, "no pocos dibujos de los obgetos y mosaicos que habrán de describirse... que se ha prestado a facilitármelos, deseoso de que salgan del olvido, así como otras observaciones y advertencias del mayor interés, adquiridas sobre el mismo terreno de Itálica en el

15. En un artículo de 1861, «Epigraphische Reiseberichte aus Spanien und Portugal», informe a la «Gesammtsitzung vom 10. Januar 1861», Monatsberichten der Königlichen Akademie der Wissenschaften zu Berlin (Phil.-Hist. Klasse), 1861, especialmente 92-93, Hübner definió la publicación de Ivo de la Cortina como "seine (elenden) Antigüedades de Itálica», es decir, "miserables», lo que seguramente no habría publicado en España, donde se trató con reverencia a su empresa científica, y a él mismo más allá de la hospitalidad debida a un huésped. Con un "bescheiden» quizá hubiera bastado.

16. Corpus Inscriptionum Latinarum. II. Hispaniae. Supplementum, Berlín, 1892, p. XCV.

17. F. Fernández Gómez, op.cit., 86 (de donde J. M. Luzón Nogué, op.cit., 78). Parte del contenido del manuscrito de largo tiempo que dirigió aquellas excavaciones» ${ }^{17}$. Aunque esta noticia hacía concebir esperanzas acerca de que el manuscrito extenso de Cortina pudiera haberse conservado también en el lote de documentos de los hermanos de los Ríos que adquirió en los pasados años 60 y custodia el Museo Arqueológico de Sevilla, la propia publicación de 1998 parece demostrar que no es así ${ }^{18}$. A raíz de esta constatación, lo he buscado en otras bibliotecas y archivos, por el momento con tanto interés como poco éxito, por lo que tiendo ahora a pensar que quizá el número de páginas manuscritas que citó Hübner, 147, pudiera corresponderse con las 52 publicadas, o bien que algunas de ellas pueden estar incorporadas en el propio manuscrito inédito, ya citado ( $c f$. supra notas 5 y 17), de Demetrio de los Ríos.

Sobre la rareza de esta obra de don Ivo, por poner otro ejemplo, valga decir que la Biblioteca Nacional de Madrid no dispone de ningún ejemplar, como tampoco la de Palacio, y, por más que el CD-ROM del Patrimonio Bibliográfico Español abre dos entradas para Cortina (como autor literario y como dibujante), no indica ninguna biblioteca pública que lo tenga en sus fondos ${ }^{19}$. Aunque determinado colega, italicófilo apasionado, ha conseguido alguno, el único ejemplar público disponible completo, aunque todavía muy poco consultado, sigue siendo el que guarda la Biblioteca Colombina de Sevilla ${ }^{20}$. Por su parte, la Real Academia de la Historia de Madrid parece conservar sólo los dos primeros fascículos, con la introducción sobre Itálica y el estudio de la cabeza que él llama "de Minerva».

Según el propio autor, el título general de su obra era Antigüedades de Itálica, y de ella sólo se llegaron a publicar los fascículos de sus trabajos de campo -esto es, más o menos su «memoria de las excavaciones»-, que llamó, a modo de capítulo interno, Escabaciones de Itálica (sic), Sevilla, 1840 (lám. 2). Esta aparente duplicidad ha dado lugar a

José Amador, finalmente inconcluso e inédito, se halla incorporado en la propia obra de su hermano menor, Demetrio, que consiguió terminarla pero no publicarla y lo será, D. m., en breve ( $c f$. nota 5 in fine) acompañada por fin, gracias a la gentileza del Dr. Fernández Gómez, de las 50 preciosas láminas que dibujó para acompañarla, halladas décadas antes que el manuscrito mismo y ya publicadas ( $c f$. nota 10$)$.

18. F. Fernández, ibid., no hace referencia de ello.

19. Pero no me cabe duda de que diversas y antiguas bibliotecas privadas sevillanas y madrileñas tienen que tenerlo aún.

20. Sección Impresos, Sevilla, sign. 82-1-53, ahora consultable también en microfichas. 


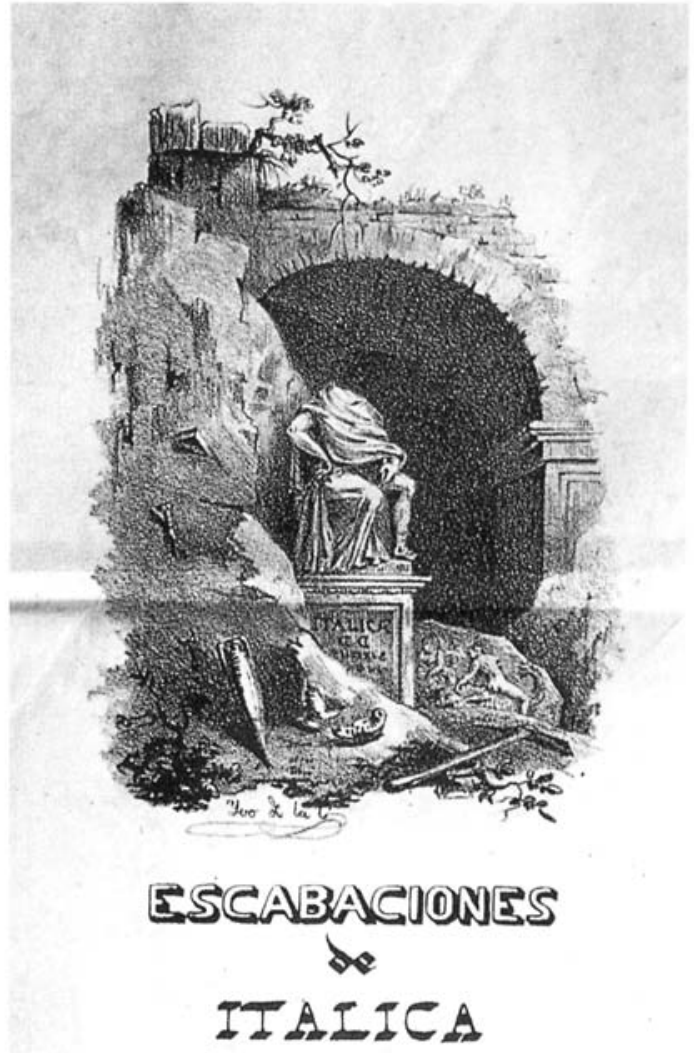

Lám. 2. "Escabaciones de Italica». Portada de fascículo del primer tomo de la obra Antigüedades de Itálica de Ivo de la Cortina, Sevilla 1840. Firmado abajo a la izquierda: Yvo de la $C$ (ortina). En el pedestal se lee ITALICAE y D D (invertidas). El arco de fondo está inspirado en el de Trajano de Mérida. (Foto tomada de:J.M. Luzón Nogué, Sevilla la Vieja. Un paseo histórico por las ruinas de Itálica, Sevilla, 1999, p. 75).

confusiones que espero ahora poder despejar de su mano, mediante el citado breve escrito que hasta este momento ha permanecido en la sombra.

21. A. Gali Lasaletta, op.cit., pp. XII y 208.

22. Con destino a una Historia de las excavaciones de Itálica que llevo avanzada hasta 1903, y que había comenzado el año anterior, con idea de conmemorar el vigésimo aniversario de la muerte de Antonio García y Bellido; otros afanes me obligaron a ralentizar aquel estudio.

23. J. M Mazón Nogué, op.cit., 75 con nota 130: Cita esta frustrada publicación por cuadernos como Excabaciones en Itálica (sic), Sevilla, 1840, y ofrece en la misma página la foto de su portada, donde más bien se lee Escabaciones de Itálica. Sin embargo, en su listado bibliográfico (p. 226) no lo cita de la misma forma, sea una u otra, que en el texto, sino como Antigüedades de Itálica, que era el nombre más tradicional de la obra de Cortina y, como aquí podemos comprobar ahora, el auténtico. En cuanto a A. Caballos et al., op.cit., p. 45 y fig., hacen lo mismo: Dan Escabaciones de Itálica como portada de la obra, pero
En el $\mathrm{n}^{\mathrm{o}} 215$, de 1 de enero de 1840, del diario El Corresponsal -vespertino de Madrid que había comenzado a publicarse el 1 de junio de 1839- el por entonces director arqueológico oficial de Itálica, Ivo de la Cortina, publicó un anuncio, redactado y firmado por él mismo, de la obra que sobre la ciudad romana había comenzado a dar a la imprenta. Proyectaba, como entonces era relativamente frecuente, publicarla por cuadernillos mensuales. Esta forma de publicación, en éste como en otros casos, encubría realmente la imposibilidad del autor de encontrar otros medios para ello, como afirma expresamente A. Gali Lassaletta, considerando, todavía a fines del XIX, que éste era un medio menesteroso de publicar, y aplicándolo expresamente al caso que estudiamos: "... igual suerte cupo á D. Ivo de la Cortina, pues á la limosna tuvo que recurrir para dar á la imprenta lo poco que publicó..." y, más adelante: "...de la limosna y suscripción metálica que le proporcionaron varios amigos....»"

Me tropecé con este Anuncio en 1992, cuando hacía en la Biblioteca Nacional una paciente revisión de los microfilms de este periódico (de la colección procedente de la Biblioteca Real), por si encontraba más noticias de las excavaciones de Cortina en «el Foro», aparte de las más arriba evocadas y aparecidas en la Gaceta de Madrid ${ }^{22}$. El anuncio o prospecto interesa entre otras cosas porque, como más arriba indiqué, aclara algo que hace muy poco se acaba de volver a poner en duda, que es el título real de esta rarísima obra y que era, en efecto, Antigüedades de Itálica y no "Escabaciones de Itálica»" ${ }^{23}$, "Las Ruinas» ${ }^{24} \mathrm{ni}$ "Ruinas de Italica ${ }^{25}$. Pero, además, el texto ahora conocido aporta interesantes precisiones acerca de la personalidad y el talante científico de este valioso pero hostigado, y en todo caso hoy aún muy olvidado arqueólogo, por lo que he creído de interés, dada su brevedad y la relativa dificultad de acce-

en la bibliografía (p. 138) la citan como Antigüedades de Itálica. Está claro, pues, que parece existir en estos momentos, o poder crearse en futuros lectores, alguna confusión en torno al título mismo, que el Anuncio que aquí reproduzco ayudará a aclarar.

24. A. Gali Lasaletta, op.cit., en p. VIII: «...su explorador D. Ivo de la Cortina publicó sus trabajos en unos cuadernitos que nombró Las Ruinas, y que no concluyó de publicar, cuyos ejemplares han desaparecido, hasta el término de no conservarse en Sevilla arriba de cuatro». Sin embargo, en su pág. 208 dice: "...un libro que publicaba por cuadernos, que titulaba Antigüedades de Itálica, ilustrado con grabados, y que era una fotografía exacta de todas sus energías...». Por tanto, incluso ya en el siglo XIX existían dudas acerca del nombre de la obra.

25. Así en las referidas líneas del Espasa (cit. en nota 14), que además le hace de ella sólo el ilustrador. 
so al medio donde lo publicó (aunque no sería sin duda el único en el que se anunciara), transcribirlo aquí íntegra y literalmente. Respeto su ortografía y puntuación, y sólo me he permitido destacar, subrayándolas, aquellas frases que me parecen más significativas a los efectos que pretendo.

"ANUNCIOS./ANTIGÜEDADES DE ITÁLICA./PROSPECTO. Cuando concebi el proyecto de efectuar las escavaciones del pueblo en donde se meció la cuna del emperador Trajano, si el gobierno me otorgaba su permiso y me prestaba apoyo; no fue solo con la intencion de estraer la tierra de aquel sitio para presentar en el museo los objetos preciosos que encerrase, ni tan solo dejar espuestos al aire los edificios que estan debajo del piso; sino facilitar con todo el lujo y economía posible noticias al mundo científico; que satisfacieran su justa ansiedad, por medio de un catálogo, que sirva de itinerario á los viageros y dé á conocer el punto que ocupaban los objetos estraídos, acompañando planos y dibujos de los edificios, estátuas, utensilios, lápidas, monedas y demas monumentos.

Con este fin, pues, saldrá á luz la obra que anuncia este prospecto; la que abrirá el campo á los anticuarios, para ajitar las polémicas de arqueología, numismática y demas, que deben servir de tipo para ilustrar la historia y facilitar á los escultores y arquitectos, medios para embellecer y aumentar el catálogo que deben enriquecer las artes y las ciencias.

Se dará al público todos los meses, principiando el 15 de enero de 1840, un cuaderno en $4^{\circ}$ compuesto de 3 láminas en papel vitelado, litografiadas á la tinta, 6 páginas de impresión del mismo tamaño y su carácter de entredos, interlineado, al precio de 6 rs. vn. ${ }^{26}$ el cuaderno por suscricion en las provincias, $5^{1 / 2}$ en Sevilla y 7 rs. en venta por número suelto.

La suscricion se efectuará por trimestres ó semestres. Cada año compondrá un tomo, y el último cuaderno se presentará en la forma siguiente:

$1^{\circ}$ El plano del edificio ó edificios escavados, representado por lámina doble del tamaño de los demás, donde por numeración, se indicará el sitio que ocupaban las estátuas, lápidas y otros

26. Es decir, "6 reales de vellón».

27. En esta época, y ya desde el siglo XVIII, con "perspectivas» se referían a los alzados de los edificios.

28. Es evidente, por tanto, que la que conocemos (véase supra) no es "la portada del libro», porque el título no le corresponde y porque ésta sólo se publicaría con la última de las entregas (a la que nunca se llegó), sino la del o los fascículos primeros, en todo caso la del tomo del primer año, donde daba noticia de sus propias excavaciones de 1839-1840 (o sea, como ya dije, su especie de «memoria de excavación»).

29. No sería quizá muy difícil seguir el rastro de los depósitos de estas librerías, por ver dónde pudieron ir a parar sus fondos. La de Pons al menos sigue hoy en todo vigor.

30. Maravedíes. objetos descriptos en los cuadernos anteriores.

$2^{\circ}$ Cuatro láminas, representando las perspectivas

${ }^{27}$ mas notables litografiadas en un claro oscuro.

$3^{\circ}$ Una id. de las monedas nuevas ó mas raras que se hayan estraido.

$4^{0}$ Una idem alegórica, correspondiente á la portada del tomo.

Se distribuirá la parte literaria en la misma forma que los cuadernos anteriores, añadiendo solo el índice de las materias contenidas en el tomo.

Como mi intencion es según dejo espresado, presentar documentos para que se discuta la aplicación de los objetos por los hombres mas conocedores en la ciencia, para aumentar las noticias que deben ilustrar la historia y admirar el porvenir en el museo sevillano, sin dejar de omitir mi opinion, incluire con gusto las disertaciones que los inteligentes se dignen remitirme con la cualidad de venir francas de porte á la imprenta donde se admiten las suscriciones.

Tendrán lugar estas en las librerías siguientes: en Madrid, á don Juan Pons Isabela, calle ancha de Peligros núm. 5 cuarto principal. En Barcelona, imprenta y librería de don Antonio Bergues. En Sevilla, imprenta frente á Sta. María de Gracia y calle de Génova, librería de don Antonio Alvarez ${ }^{29}$.

NotA. Se advierte al público que el autor cede de su propiedad para el fondo de las escavaciones 16 mrs. ${ }^{30}$ por cada ejemplar que se espenda. - Ivo de la Cortina."

Es fácil extraer buenas conclusiones de la simple lectura. Personalmente me llaman la atención sobre todo su deseo ilustrado, igual al que años después manifestaría Demetrio de los Ríos, de no excavar por excavar o por hallar bellezas museables, sino dar luz verdadera a la Historia. Esto concuerda muy bien con los criterios realmente ilustrados que se habían instaurado con fuerza en España en especial durante el reinado de Carlos IV de Borbón (1788-1808), aunque se trate de una realidad poco conocida y valorada hasta hace poco $^{31}$. Del mismo modo encaja en ello la modernidad de sus planteamientos en cuanto a la

31. La hipótesis fue esbozada por quien suscribe en 1994: «La Arqueología española bajo Carlos IV y Godoy: Preludio a los dibujos emeritenses de Villena Moziño (1791-1794)», Anas 7-8 (Homenaje a J. Álvarez y S. de Buruaga), 1994-1995, 31-56. El asunto fue tratado más tarde en extenso y con la documentación precisa: Alicia $\mathrm{M}^{\mathrm{a}}$ Canto, La Arqueología española en la época de Carlos IV y Godoy. Los dibujos de Mérida de don Manuel de Villena Moziño, 1791-1794 (Fundaciónes de Estudios Romanos y El Monte, Ministerio de Educación y Cultura), Madrid, 2001, así como en Mérida y la Arqueología Ilustrada: Las láminas de don Manuel de Villena (1791-1794) (catálogo de la exposición en el Museo Nacional de Arte Romano de Mérida junio-octubre 2001, prólogo de $\mathrm{D}^{\mathrm{a}}$ Pilar del Castillo), Madrid, 2001. 
documentación de los hallazgos incluída la precisa ubicación de cada resto, como él mismo acababa de hacer en Mérida y haría más tarde en Itálica Demetrio de los Ríos, mediante sus conocidos planos topográficos ${ }^{32}$. Junto a ello, no deja Cortina de referirse a la exigencia de que el excavador se ocupe también del legítimo afán e incluso necesidad de los simples aficionados o viajeros de poder orientarse convenientemente en un yacimiento ${ }^{33}$, de dar a conocer los fondos del museo sevillano y de que los objetos bien dibujados puedan servir de nuevo material a escultores y arquitectos.

Pensando ya en los expertos, quiere "abrirles campo", facilitar a la comunidad científica las noticias de una forma rápida (atendiendo a "su justa ansiedad»), pero no sólo para su exclusivo conocimiento, sino también "para agitar las polémicas de arqueología, numismática y demás». Las polémicas son desde hace unas décadas algo rehuído, casi temido, en la Arqueología española, pero eran sin embargo normales y frecuentes entre los anticuarios del pasado (a veces sazonadas con algo de ironía y hasta verdaderas sátiras), y eran y son vehículo inseparable de la ciencia ${ }^{34}$.

Satisfaciendo ya todos estos saludables criterios de don Ivo a un planteamiento moderno de la Arqueología, otros dos detalles soprenden también agradablemente. Uno es el que, como puede leerse en la nota final, anunciaba que destinaría una parte de sus propios beneficios de la venta del libro a financiar las excavaciones de Itálica. El gesto era más de agradecer en él, por cuanto a estas alturas tenía ya cuatro hijos que mantener y se trataba de una persona a la que los problemas económicos amargaron casi durante toda su vida ${ }^{35}$. ¿Cuántos casos de éstos podríamos contar en nuestros días, si no existieran las generosas, a veces suculentas, subvenciones

32. A. M ${ }^{\mathrm{a}}$ Canto, «La Vetus Urbs de Itálica, quince años después. La planta hipodámica de D. Demetrio de los Ríos, con otras novedades», Cuadernos de Prehistoria y Arqueología de la U.A.M. 25.2, 1999, 145-191, véanse espec. 166 ss. y sus láms. 4 a 7, con las referencias correctas de sus fechas y la bibliografía anterior.

33. Ésta es una diferencia muy elogiable hacia la sociedad aficionada pero no experta, que refleja en otros escritos suyos en los que él mismo se considera "un viajero arqueólogo... que vierte las impresiones de su viaje hasta donde alcanza su humilde criterio de medio siglo...» (A. M. Canto, art.cit. en nota 12 ).

34. Parece ser un hecho que sólo los realmente grandes o muy abiertos de mente afrontan la polémica. Creo que don Ivo pensaba, como algunos otros, y quizá algo ingenuamente, que había más grandes en su época de los que realmente había. públicas, destinadas a financiar excavaciones cuya calidad y resultados científicos tantas veces dejan que desear, son en realidad intrascendentes o incluso quedan inéditos?

El otro, y más importante, es su ofrecimiento final de que él mismo publicaría sin problemas en sus fascículos (isiempre que no se las mandaran a cobro revertido!) las opiniones diversas o los artículos de otros autores «inteligentes» sobre las novedades y estudios que se publicaban. Lo que estas líneas proponían era algo habitual en Europa pero sin duda un experimento pionero en España y que, hasta donde sé, el propio mundo académico, el de los eruditos que lo despreciaban y atacaban desde las sombras, no había intentado a la altura de 1840. Pero no sólo no hubo «inteligencia» suficiente para aceptar su ofrecimiento y colaborar a esta oferta de la que hubiera sido una fecunda Revista Arqueológica de Itálica, y quizá con el tiempo el embrión de una verdadera Revista Arqueológica de España ${ }^{36}$, sino que al poquísimo tiempo de plantear sus resultados y sus proyectos futuros, otros "expertos», más estrechos de mente, celosos de su talento e iniciativa -como ya dijo Aurelio Gali Lasaletta en 1892 (ibid.), al considerar a don Ivo una víctima de «la huéspeda», o sea, de "envidiosos y obstruccionistas, fruta siempre madura...»-, consiguieron echarle de Itálica, como también harían con Demetrio de los Ríos y, más tarde, con su sobrino Rodrigo-Amador de los Ríos.

Este último, eminente polígrafo como su padre, en unas amargas pero a todas luces muy sinceras líneas, y mencionando expresamente en nota a Ivo de la Cortina, echa la culpa de estos enconos al hecho de no ser ninguno de ellos sevillano: "Varios, y más o menos graves, son los inconvenientes con que he tropezado en el curso de las excavaciones hasta aquí bajo mi dirección en el anfiteatro

35. J. M. Luzón Nogué (op. cit., 83 y nota 158), basándose en un escrito de Cortina de 9 de septiembre de 1875 conservado en el más atrás citado expediente del AGAE, ya resalta que en 1875 Ivo de la Cortina se hallaba casi en la miseria. En el mencionado próximo estudio podré corroborarlo con otros documentos, así como que el 20 de abril de 1876 solicitaría ya su jubilación, alegando haber cumplido hacía unos meses (en diciembre, como dije al principio) los 70 años de edad.

36. Puesto que Cortina ya en estos primeros fascículos no trataba sólo de la famosa ciudad, sino también de Mérida, de Murcia y de otros lugares: véase ad ex. Antigüedades de Itálica, pp. 27-28 (excavaciones de 1832 en los alrededores de Murcia), o su lám. I (Arco de Trajano de Mérida), etc. 
practicadas, prescindiendo de la situación del mismo, de la escasa consignación que señalada tienen, y de la enemiga con que es por ciertos intelectuales hispalenses mirada la persona no nacida en Sevilla que las tenga a su cargo, cual en 1840 hubo de acontecer respecto de don Ibo de la Cortina... (nota 2). Conforme el mismo Sr. Cortina expresa, y quedó apuntado en una de las notas de este trabajo, aquellas excavaciones "decayeron en 1839 por las intrigas de un hombre miserable (esto en cursiva), y... perecieron luego en 1840”. Algo de esto ha ocurrido también conmigo, por no ser sevillano.... ${ }^{37}$.

Ya sorprende bastante esta acusación cuando sabemos que la familia de los Ríos era andaluza, cordobesa de Baena según dijimos ${ }^{38}$. Pero, si esto fue así (y nos lo dice una fuente bien documentada y la más autorizada para hacerla), cuánto más natural veríamos tal miopía científica y tal penoso aldeanismo de "ciertos intelectuales hispalenses» ${ }^{39}$ dirigido contra Cortina, que por su nacimiento, no lo olvidemos, era catalán. Este nuevo e insospechado factor, aportado a nuestro análisis por Rodrigo Amador de los Ríos en 1916, quizá acabaría explicando por qué el tener la misma ideología liberal que los miembros de la Junta Revolucionaria de Sevilla, e incluso el haber trabajado para su triunfo, no consiguieron salvar al laborioso e innovador don Ivo del cese por la misma, en $1840^{40}$.

37. R. A. de los Ríos, «El anfiteatro de Itálica. Noticias acerca de este monumento y de las excavaciones que en él, de orden del Gobierno, se practican», Revista de Archivos, Bibliotecas y Museos 7-8, 1916 (2 $2^{\mathrm{a}}$ parte: Conclusión), 1-24. El párrafo que copio está en la pág. 20 con su nota 2 . En la frase de Cortina que él cita, las palabras "por las intrigas de un hombre miserable», aparecen destacadas en cursiva, por lo que sospecho que don Rodrigo, como Cortina, tenía entre sus varios enemigos hispalenses uno más grande, poderoso y miserable. Pero, al igual que su predecesor, se abstuvo de citarlo por su nombre, razón por la cual hoy no es fácil saber de quiénes se trataba en cada caso (pero véase la nota 39 ).

38. Rodrigo había nacido en Madrid por el traslado de su padre a la capital; pero éste siguió vinculado a ella, al punto de morir en Sevilla, en 1878, y de estar enterrado con honores en la Universidad hispalense, donde el propio Rodrigo había estudiado, según él mismo recuerda en el Prólogo de su opúsculo La Leyenda del Rey Bermejo (Barcelona, 1890). Pero parece que todo ello no era suficiente.

39. Afortunadamente, no en todos: Recordemos ahora cómo la Academia de Sevilla había protegido a Cortina en 1839 ante la de la Historia, y luego otra vez frente al cese de 1840 (supra nota 1). De estos datos imagino que la persona en cuestión al menos no pertenecía a la academia hispalense, o bien estaba en minoría en ella y, en cambio, tenía presencia y/o influencia en la Junta de Sevilla. Quizá algún colega sevillano actual pueda aportar más elementos para perfilar mejor lo acontecido.
Al molestar, perseguir, calumniar y conseguir expulsar de Itálica a Cortina -tras lo cual sobrevino una nueva y espantosa etapa de expolios y ventas ilegales de objetos del yacimiento-, algunos de tales presuntos «inteligentes» dieron al traste también con otro de los pocos, breves, y por lo general traumáticamente terminados periodos de bonanza científica, de los que, sólo poco y de vez en cuando, disfruta hasta hoy esta a la vez afortunada y desgraciada ciudad, víctima de su «violenta Némesis», como cantó Rodrigo Caro o, para ser más exactos, con estas palabras concretas, Francisco de Rioja.

Y todo ello a pesar de ser la única ciudad del Imperio, exceptuada Roma, que puede enorgullecerse de haber alumbrado a dos dinastías béticas, y al menos a tres emperadores ${ }^{41}$.
40. Véase la nota anterior, y supra. Los primeros ataques le habían llegado a don Ivo desde Madrid, y nada menos que de la Real Academia de la Historia, pero ipuede suponerse que a petición de algún numerario o correspondiente hispalense? Lo cierto es que debía de tener también muy poderosos enemigos en la propia Sevilla y, dada su extracción y actividad no académica, era más fácil presa del mundo de los «intelectuales».

41. Acabo de defender (y espero que de demostrar) que la patria natal de Teodosio el Grande no pudo ser «Cauca de Gallaecia» (h. Coca, Segovia) y que, en efecto, tal como siempre fue tradición en la bibliografía italicense anterior al siglo XX, el último emperador del Imperio unido había nacido, si no en la misma Itálica, sí en su más inmediato territorium. Todavía se elevarían de tres a cuatro los emperadores italicenses si el hijo mayor de Teodosio, Flavio Arcadio, futuro emperador de Oriente, nacido en el año 387 d.C. y por tanto durante el autoexilio político de Teodosio en Hispania, pudiera haber tenido, como sería lógico, la misma cuna. Se podrán ver para ello mi monografía inédita El clípeo de Teodosio el Grande de la Real Academia de la Historia de Madrid. Una revisión profunda de la mejor pieza de la Arqueología española, Madrid, 2000, y el artículo «Sobre el origen bético de Teodosio I el Grande, y su improbable nacimiento en Cauca de Gallaecia», en prensa en la revista Latomus (Bruselas), 2004. 